\title{
Finite-Element Analysis on Seismic Behavior of Hexagonal-Hole Variable Cross- Section Honeycomb Beam Portal Rigid Frame
}

\author{
Feng XU \\ Department of Civil Engineering \\ Shenyang Jianzhu University \\ Shenyang, China \\ E-mail: xuyongfeng@126.com
}

\author{
Lei TONG \\ Department of Civil Engineering \\ Shenyang Jianzhu University \\ Shenyang, China \\ E-mail: 408239318@qq.com
}

\author{
Qinggang LI \\ Liaoning Provincial Building Design \& Research Institute \\ Shenyang, China
}

\begin{abstract}
In order to analyze the seismic performance of the hexagonal-hole variable cross-section honeycomb beam portal frame, the finite element analysis software ABAQUS is used to analyze the seismic behavior of the portal frame with the same span, same beam-to-column distance, hole number, opening ratio is $50 \% \sim 80 \%$ of the regular hexagonal-hole variable cross-section honeycomb beam portal rigid frame for analysis and comparison, the force characteristics of hexagonal-hole variable cross-section honeycomb beam portal rigid frame under low-cycle cyclic loading are obtained. This paper compares and analyzes the seismic behavior of hexagonal-hole variable cross - section portal frame with different opening ratio under earthquake action, such as the stress process, failure mode, hysteretic curve, skeleton curve, stiffness degradation and ductility. The plastic hinge of the structure is located at the first honeycomb hole near the beam end and away from the beam-column connection node, which reduces the possibility of brittle fracture at the weld of the variablesection portal frame beam-column joint and improves the turning ability, good ductility of steel can be fully played. The bearing capacity, ductility and stiffness of the portal frame with the solid web are gradually decreased with the increase of the opening rate. The seismic performance of honeycomb variable cross-section portal frame as the original solid web portal frame, but it has light weight, good economic benefit, both beautiful and advantages in the holes through the pipeline equipment layout, and has great practical value in actual engineering application.
\end{abstract}

Keywords-variable cross-section; opening ratio; seismic behavior; low-cycle load; plastic hinge

\section{INTRODUCTION}

With the increase in China's steel production and steel structure industry vigorous development, the light steel structure has been widely used in various kinds of buildings, the portal frame structure building with its simple structure, less steel consumption, high degree of industrialization production of a series of advantages, is widely used in in China's low-rise large space building. Variable cross-section light portal rigid frame is a cleverly designed structural system, in the "best use" principle, according to the size of stress design component size, variable cross-section to pursue equal strength, can save a lot of steel. At the same time, the honeycomb beam compared with plain girder, the honeycomb beam is of light weight, good economic benefit, the beam hole in the web openings, both beautiful and can be ventilated, but also in the hole through the layout of equipment pipelines, to ensure that buildings under high conditions, reduce the building height, full use of the building space, therefore, honeycomb beam in the practical application of the project has great practical value [1].At present, the developed countries in the field of honeycomb beam design and calculation have been standardized, tabular, automated, some countries have honeycomb beam design into the specification [2]. The calculation formula of the honeycomb beam is listed in the British steel structure code BS5950Part1[3]. The research personnel of our countryreword have done some research on the honeycomb beam, and have carried on the popularization and application. However, there are few studies on the portal frame with variable cross- section in the open-hole of the beam web. In this paper, we will directly open a hole in the beam web of the variable cross-section portal frame, combined variable cross-section portal rigid frame with honeycomb beam. The seismic behavior of the portal frame with variable cross section is compared by using the finite element software.

\section{The EStablishment OF THE FinITE ELEMENT MODEL}

\section{A. The Finite Element Model Design}

The author based on the model of Sun Hongda[4]'s referencing style honeycomb frame structure system under low cyclic loading, the finite element analysis is carried out for the finite element method. The comparison between the results of finite element analysis and the experimental data is in good agreement, which verifies the feasibility of the finite element analysis. Therefore, this paper uses the general finite element software ABAQUS CAE to establish the finite element model, Select C3D8R (8 hexahedron reduced integration unit). The beam column joints are considered as rigid nodes, and the tie constraint in the software is used to simulate the weld joint, and ignore the influence of the 
welding residual stress. The column using the rigid form, in order to ensure the beam out of plane stability, the degree of freedom of the flange beam in the plane constraint software. The Q235 is chosen as the steel material. The constitutive relation of the material is reinforced by three-fold line model. The Bauschinger effect is not considered. The yield criterion of the steel is Von-Mises yield criterion[5].Due to the weakening of the overall rigidity of the web portal girder web and the large deformation under load, geometric nonlinearity and material nonlinearity should be considered in order to accurately predict the large deformation of the structure and the stress redistribution after the plastic hinge formation [6].

The finite element model is designed according to the portal frame according to 02SG518-1[7], which is the standard frame of light steel structure of portal frame. Its span is $24 \mathrm{~m}$, height is $6.9 \mathrm{~m}$, roof slope $1 / 15$, beam section size $\mathrm{H}(750-450) * 160 * 8 * 6$, column section size $\mathrm{H}(675$ $300) * 240 * 8 * 6$.The finite element model based on the dimension is shown in Fig.1 by using ABAQUS CAE pretreatment module.

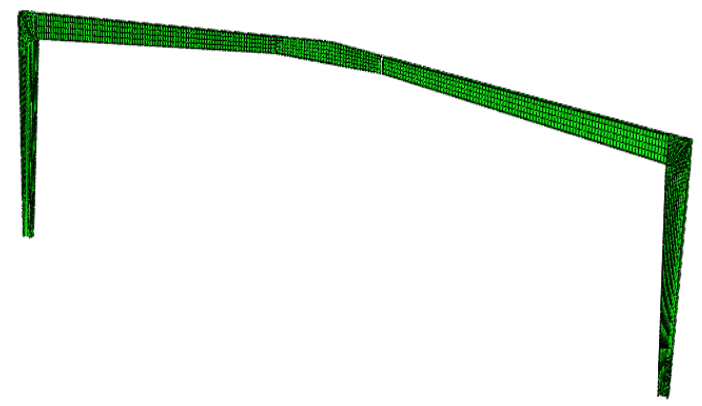

Figure 1. Finite element model

This paper establish a solid abdominal variable crosssection portal frame and four in the beam at both ends to ensure the bulk of the first cross-section of the hole to the column flange distance $750 \mathrm{~mm}$ unchanged under the premise of different cellular rate of the variable cross-section honeycomb beam portal frame. Model number 2400, 2405, 2406, 2407, 2408 respectively represent the variable real abdomen, the opening rate of $50 \%$ 80\% of the variable cross-section honeycomb beam portal frame. As shown in Fig. 2 for the aperture ratio of $60 \%$ of the variable crosssection honeycomb beam portal frame.

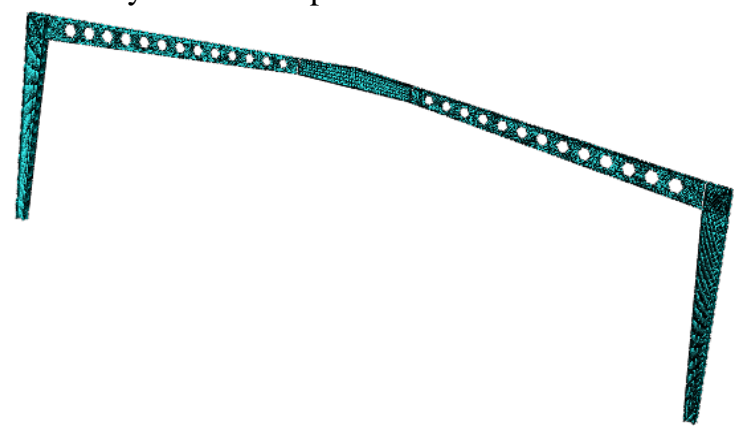

Figure 2. Finite element model 2406

\section{B. $\quad$ Model Loading}

Structural loads are calculated according to the code for load of building structures, uniform load on the top of rigid frame beam with $6.6 \mathrm{KN} / \mathrm{m}$. Structural weight is calculated by the finite element analysis software by inputing acceleration of gravity into the model. Lateral displacement is applied to the portal frame to obtain the loaddisplacement curve of each portal frame. And the yield displacement $\Delta_{\mathrm{y}}$ of each portal frame is predicted and the horizontal reciprocating displacement is applied to $\pm 0.5 \Delta_{\mathrm{y}}$, $\pm 1 \Delta_{\mathrm{y}}, \pm 1.5 \Delta_{\mathrm{y}}, \pm 2 \Delta_{\mathrm{y}}$.

\section{Structural Failure Criterion}

(1) The failure of steel structure is mostly ductile failure. In order to simulate the ductile failure of steel, the three broken line model of the finite element model is adopted in this paper. If the element stress of a certain section of the structure reaches the falling section at the same time under the action of external load, the plastic hinge will be formed in the cross section, and the program will be interrupted when solving the finite element equation, which indicates the structural damage [8].

(2) The bearing capacity of the structure is reduced to 0.85 times of its ultimate load.

(3) The structure of large deformation or software calculation does not converge to break the operation can be considered that the structure has been destroyed.

\section{The Simulation Results AnAlysis}

\section{A. Static Loading}

Fig. 3 shows the load-displacement curves of variablesection honeycomb beam portal frames with different perforation rates under a single static load.

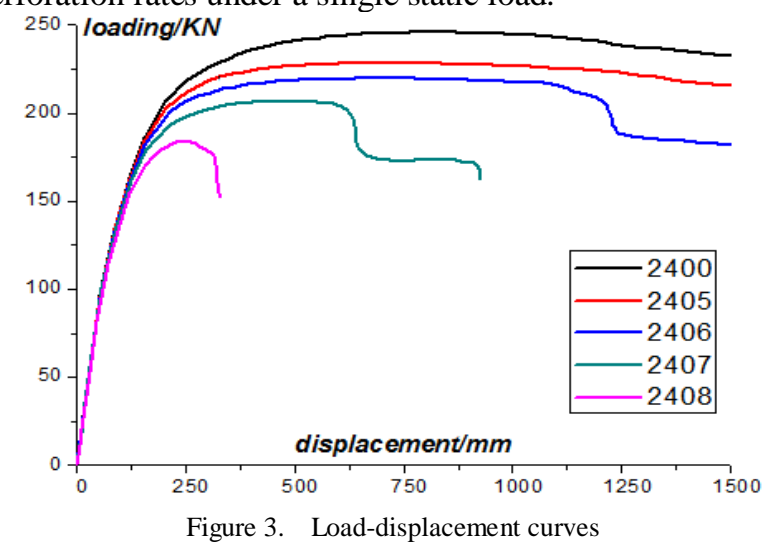

It can be seen from the curve that the carrying capacity of the portal frame with solid web is the largest, with the increase of the opening rate, the bearing capacity is gradually reduced, in the later stage of the loading of portal frame, $60 \%, 70 \%$ and $80 \%$ of the perforation rate of the steel structure is obviously degenerated due to the weakening of web opening, of which the opening rate of $80 \%$ of the fastest degradation of the portal frame. According to the load displacement curve under uniaxial static load, the yielding 
displacement $\Delta_{\mathrm{y}}$ and the yield load $\mathrm{P}_{\mathrm{y}}$ of the portal frame are calculated by the "general yield bending moment method".

\section{B. Low Cycle Reciprocating Loading}

\section{1) Finite element simulation results}

Fig. 4 shows the form of the failure of the model 2406. Figure 4 as an example, the failure of the portal frame with variable cross section honeycomb beam after opening is in the position of the first hole at both ends of the beam. Because of the stress at beam-to-column joints, the crosssection of the web is weakened partially after opening the hole. After opening the hexagonal hole, the stress is concentrated at the corner of the hole, and the honeycomb hole is yielded under the low-cycle reciprocating load. After the upper and lower flange also occurred more obvious yield phenomenon, the upper flange of the left end of the beam is more buckled than the lower flange, the right end of the beam is the opposite. Compared with the portal frame with variable cross-section, the honeycomb variable cross-section honeycomb beam portal frame has successfully achieved the goal of plastic hinges to be moved outward, which reduces the possibility of brittle failure and minimize the harm.
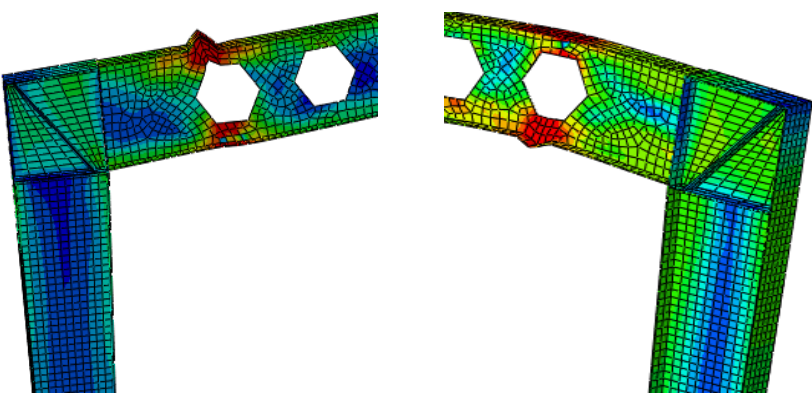

Figure 4. Model 2406 failure mode diagram

\section{2) $P-\Delta$ Hysteresis curve}

$\mathrm{P}-\Delta$ hysteresis curve is the load-deformation curve of the structure under the force cyclic reciprocating action. It can reflect the deformation characteristics, stiffness degradation, strength attenuation, energy dissipation capacity and ductility of the structure during the repeated stressing process. It is also the main basis for determining the restoring force characteristics when the structure is subjected to elasto-plastic seismic response analysis.Fig.5 shows the P- $\Delta$ hysteresis curve of the honeycomb beam portal frame with variable opening ratio under the low cyclic reciprocating load.

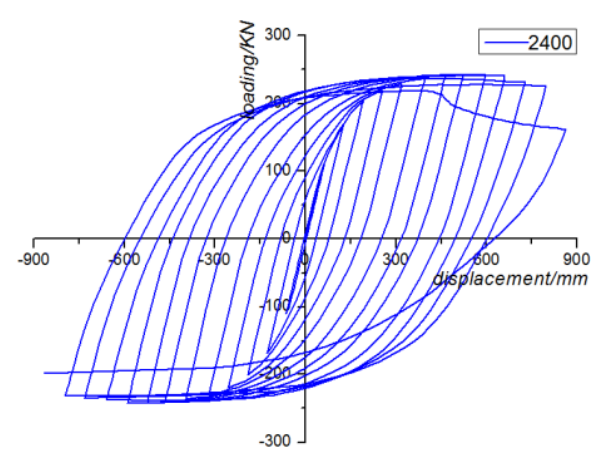

(a) 2400- hysteresis curve

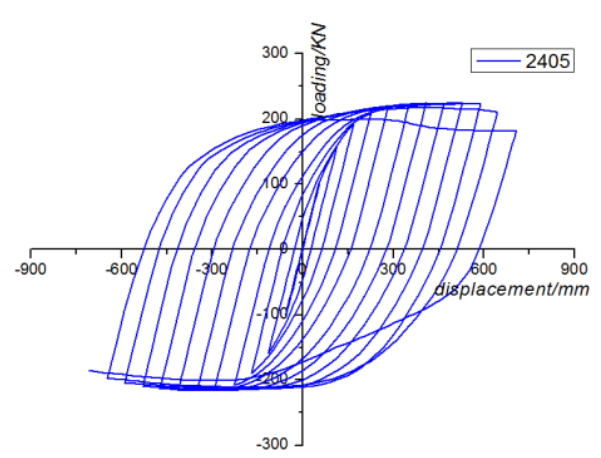

(b) 2405-hysteresis curve

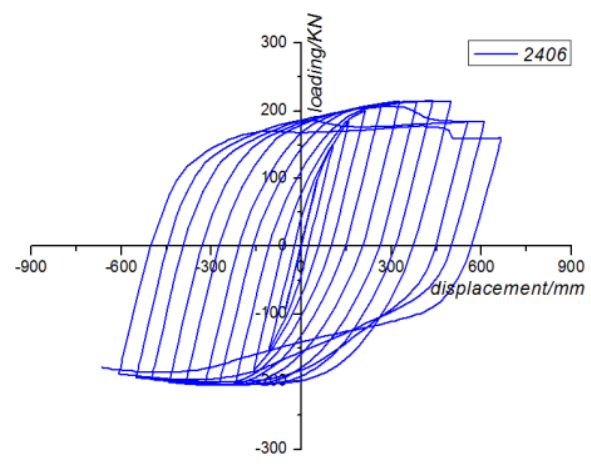

(c) 2406-hysteresis curve

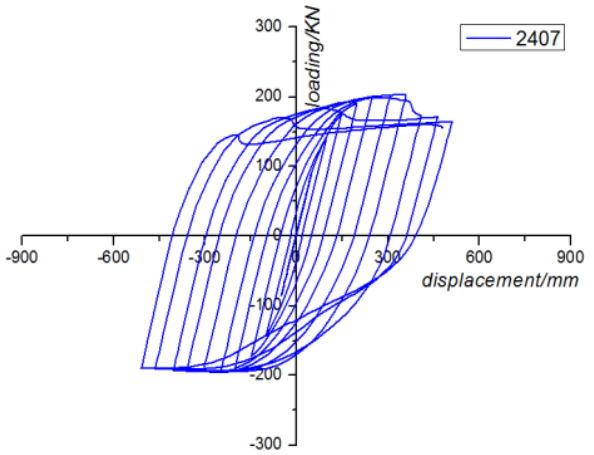

(d) 2407-hysteresis curve

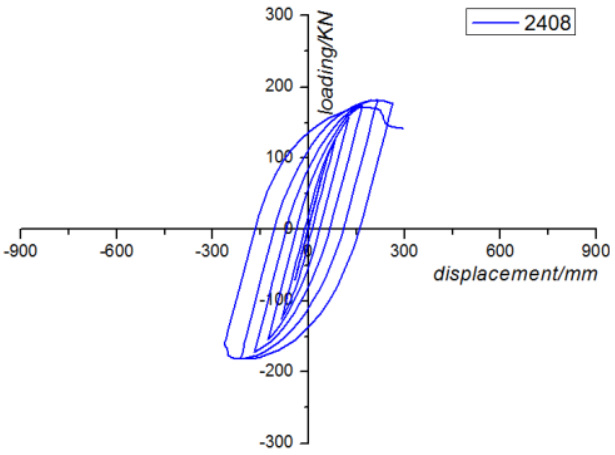

(e) 2408-hysteresis curve

Figure 5. Hysteresis curve contrast figure 
The hysteresis curve of each portal frame is shown in Fig. 5.The shape of the five hysteresis curves are spindleshaped, and the shape of the model 2400 is the most plentiful, which shows that this structure has strong plastic deformation ability. With the increase of the opening ratio, the area enclosed by the hysteresis curve is getting smaller and smaller, which reflects that with the increase of the opening of the web, the weakening of the cross-section becomes more and more serious, and the energy dissipation capacity of the structure decreases gradually. The hysteresis performance of the portal frame with $80 \%$ open-hole ratio is the worst. The reason is that the opening of the web is excessively large and the cross-section weakened too seriously.

\section{3) Skeleton curve}

The skeleton curve is the curve of the hysteresis curve which is connected with the load extreme points of the same load (pull or press). The skeleton curve is the trajectory of the maximum peak value of the horizontal force reached by each cycle loading, which reflects the various stages and characteristics (strength, stiffness, ductility, energy dissipation and anti-collapse ability).But also an important basis for determining the characteristic points in the model of restoring force.

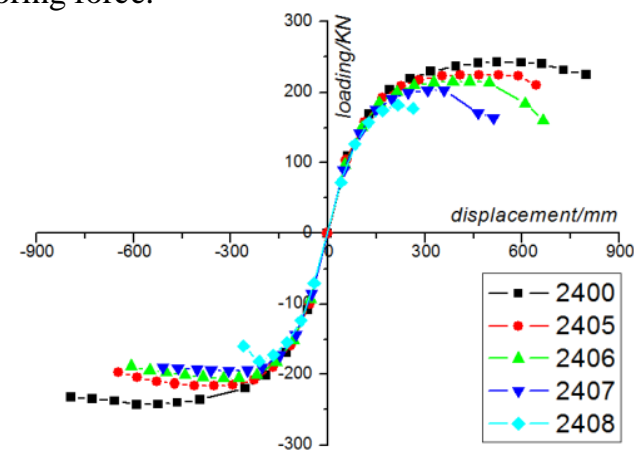

Figure 6. Skeleton curves of each portal rigid frame

It can be seen from Fig. 6, the skeleton curve of the portal frame has little difference in the early stage of loading, and the ultimate bearing capacity and rigidity of the structure decrease with the increase of the opening ratio. The skeleton curves of model 2400-2407 are smoother, and there is no obvious abrupt change point, which shows that the yield process of portal frame is relatively gentle, and there is no sudden damage to the web due to the weakening of beam web. From local yield, ductility develops, cracks appear, and gradual expansion is a ductile failure. The development trend of model 2408 is consistent with other models in the initial stage of loading, and to the plastic stage, due to the large opening of the web plate, the cross section is weakened, the bearing capacity is decreased rapidly to the structural damage.

\section{4) Ductility and energy dissipation performance}

a) Ductility performance

Ductility is the deformation capacity of a section of a structure or member from the beginning of the yield to the maximum load capacity or after the arrival of the load capacity has not significantly decreased. In this paper, the ductility is evaluated by the displacement ductility factor $\mu$.

$$
\mu=\mu_{\mathrm{u}} / \mu_{\mathrm{y}}
$$

In the equation (1), $\mu_{\mathrm{u}}$-the limit displacement when the frame is destroyed, which is $85 \%$ of the peak displacement; $\mu_{y^{-}}$yield displacement of rigid frame.

TABLE I. TABLE OF StRUCTURAL DUCTILITY COEFFICIENT

\begin{tabular}{|c|c|c|c|}
\hline \multirow{2}{*}{$\begin{array}{c}\text { Model } \\
\text { name }\end{array}$} & \multicolumn{3}{|c|}{ Structural parameters } \\
\cline { 2 - 4 } & $\begin{array}{c}\text { Yield } \\
\text { displacement/mm }\end{array}$ & $\begin{array}{c}\text { Limit } \\
\text { displacement/mm }\end{array}$ & $\begin{array}{c}\text { Ductility } \\
\text { factor }\end{array}$ \\
\hline 2400 & 133 & 806 & 6.06 \\
\hline 2405 & 118 & 683 & 5.79 \\
\hline 2406 & 111 & 609 & 5.49 \\
\hline 2407 & 103 & 463 & 4.50 \\
\hline 2408 & 88 & 270 & 3.07 \\
\hline
\end{tabular}

The ductility coefficient of each portal frame is shown in Tab. 1. With the increasing of the opening ratio, the ductility coefficient of each portal frame decreases. The ductility of model 2408 is less than 4, which indicates that the ductility of structure is poor.

b) Energy dissipation performance

Energy dissipation is the ability of a structure or member to absorb energy under repeated forces. In this paper, the equivalent viscous damping coefficient $h_{e}$ and the energy dissipation coefficient $\mathrm{E}$ are used to analyze the energy dissipation capacity of the structure.

TABLE II. The PEAK LOAD ENERGy DisSiPATION COEFFICIENT OF STRUCTURALS

\begin{tabular}{|c|c|c|}
\hline \multirow{2}{*}{ Model name } & \multicolumn{2}{|c|}{ Energy consumption parameter } \\
\cline { 2 - 3 } & $\begin{array}{c}\text { Equivalent viscous } \\
\text { damping coefficient }\end{array}$ & $\begin{array}{c}\text { Energy dissipation } \\
\text { factor }\end{array}$ \\
\hline 2400 & 0.465 & 2.916 \\
\hline 2405 & 0.500 & 3.139 \\
\hline 2406 & 0.432 & 2.716 \\
\hline 2407 & 0.409 & 2.569 \\
\hline 2408 & 0.368 & 2.318 \\
\hline
\end{tabular}

Compared with the data in Tab. 2, when the opening ratio is $50 \%$, the plastic hinge can absorb a part of energy when the structure is damaged due to the opening of the beam web. With the decrease of the beam web section, the energy absorption capacity of the structure decreases, and the opening rate is $80 \%$. The structure energy dissipation capacity is decreased by $20.5 \%$.

\section{5) Stiffness degradation}

Stiffness degradation is a process of stiffness degradation that is the process of increasing stiffness and decreasing displacement as the load continues to be repeated. In this paper, the secant stiffness is used to express the rigidity of the portal frame under repeated loading. 


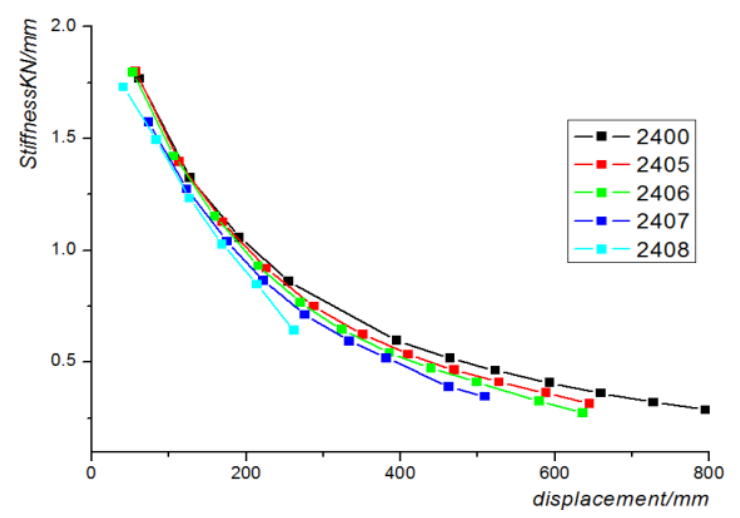

Figure 7. Schematic of stiffness degradation of structurals

It can be seen from Fig. 7 that the stiffness degradation of the rigid frame is almost the same, the degradation is more uniform, there is no abrupt change of stiffness. The rigidity of the rigid frame with opening ratio of $80 \%$ is obviously degraded and the damage is earlier. For frames with $50 \%$ and $60 \%$ openings, the former stiffness is bigger, and the latter stage stiffness degenerates smoothly without mutation, which can be adopted in design.

\section{CONCLUSION}

(1). Under the action of low cyclic loading, the honeycomb beam portal frame with variable cross section after the opening of the web is destroyed by the position of the first hole at both ends of the beam,due to the large stress at the beam column joints, the cross-section of the web opening is weakened, the stress concentration at the hole angle and the honeycomb hole yield to the failure.Compared with the portal frame with variable cross - section, the hexagonal-hole portal frame with variable cross - section has successfully achieved the plastic hinge outward displacement.

(2). According to the analysis of the finite element software, the bearing capacity, ductility and rigidity of the variable section portal frame decrease with the increase of the opening ratio. The energy dissipation capacity of the variable cross-section honeycomb beam portal frame with only $50 \%$ perforation is stronger than that of the portal frame with variable cross-section.Opening ratio of $80 \%$ of the variable cross-section honeycomb beam portal frame, due to the severe web, poor ductility, poor energy dissipation,prone to sudden damage, it should be avoided in design.

(3). Although the seismic performance of the variable cross-section honeycomb beam portal frame is not as good as that of the original portal frame, it has advantages of light weight, good economic efficiency, both beautiful and can pass through the equipment pipeline in the hole.Therefore, it is of great practical value in the practical application of the portal frame in the engineering practice.

\section{REFERENCES}

[1] Jia Lianguang, Xu Xiaoxia, Kang Xiaozhu.Finite element analysis of flexural bearing capacity of Castellated Beams[J]. Journal of Shenyang Institute of Architectural Engineering, 2005, (3); 196-199.

[2] Li Qiliang,Experimental study and finite element study on mechanical behavior of honeycomb light steel portal frame [D] .Nanning; Guangxi University, 2012.

[3] Srimani S L.Development of Design load Table for Castellated Beams.Indian Journal of Technology, 1980,18(12):494-497.

[4] Sun Hongda,Seismic performance analysis of cellular beam column steel frame structure[D].Shenyang; Shenyang Jianzhu University, 2011.

[5] Ji Ming,GaoFeng,Liao Mengke.A comparative analysis of the yield stress of several yield criteria[J].Journal of Plasticity Engineering, 2006, 13(5): 14-15.

[6] Wang Zhenshan,Research on seismic behavior of beam column joints and structures of single story and single span portal frame structure with variable cross section [D].Xi'an;Xi'an University Of Architecture And Technology, 2013.

[7] China building standard design and Research Institute,02SG5181Steel structure of light-weight buildings with gabled frames (without crane) Atlas [M],Beijing;China Standard Press, 2002.

[8] Bai Xiang,Study on the behavior of light - weight portal frame with variable cross - section under cyclic loading [D].Xi'an; Xi'an University of Science and Technology, 2012. 